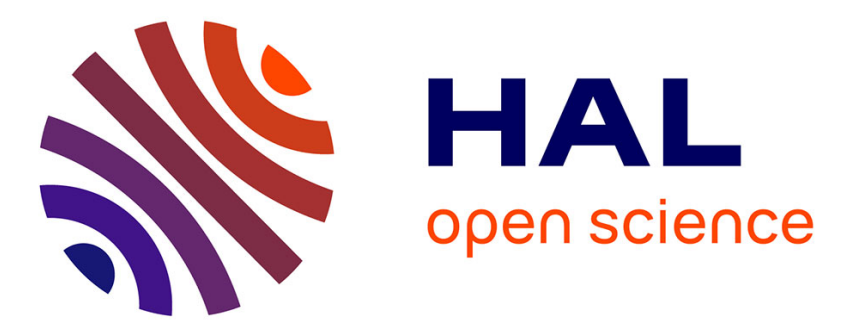

\title{
Knowledge Engineering for Enterprise Integration, Interoperability and Networking: Theory and Applications
}

\author{
Hervé Panetto, Lawrence Whitman
}

\section{To cite this version:}

Hervé Panetto, Lawrence Whitman. Knowledge Engineering for Enterprise Integration, Interoperability and Networking: Theory and Applications. Data and Knowledge Engineering, 2016, 105, pp.1-4. 10.1016/j.datak.2016.05.001 . hal-01310451

\section{HAL Id: hal-01310451 \\ https://hal.science/hal-01310451}

Submitted on 4 May 2016

HAL is a multi-disciplinary open access archive for the deposit and dissemination of scientific research documents, whether they are published or not. The documents may come from teaching and research institutions in France or abroad, or from public or private research centers.
L'archive ouverte pluridisciplinaire HAL, est destinée au dépôt et à la diffusion de documents scientifiques de niveau recherche, publiés ou non, émanant des établissements d'enseignement et de recherche français ou étrangers, des laboratoires publics ou privés. 


\title{
Knowledge Engineering for Enterprise Integration, Interoperability and Networking: Theory and Applications
}

\author{
Hervé Panetto ${ }^{1,2}$ and Lawrence Whitman ${ }^{3}$ \\ ${ }^{1}$ Université de Lorraine, Research Centre for Automatic Control (CRAN UMR 7039), France \\ ${ }^{2}$ CNRS, CRAN UMR 7039, France, Herve.Panetto@univ-lorraine.fr. \\ ${ }^{3}$ Donaghey College of Engineering and Information Technology, University of Arkansas at Little Rock, \\ Lewhitman@ualr.edu
}

\section{Introduction}

Today, enterprises can be characterized by various key facets: globalization, distributed manufacturing, data and knowledge management, advanced automation and robotics, virtual engineering, rapid response to market and more. In this competitive economy, enterprises must collaborate using Information Technology (IT) and other tools to succeed in this dynamic and heterogeneous business environment. Enterprise integration, interoperability and networking are some of the major disciplines that are enabling companies to improve collaboration and communication in the most effective way. Thriving enterprise information systems processes aim to develop information systems that respond to increasingly complex objectives, which align the information systems with business goals and processes of the company. Additionally, the enterprise must adapt and improve when facing new requirements or rapidly changing opportunities. As enterprise information systems models become more ubiquitous, the sharing of bestin-class models becomes more desirable. Interoperability between dissimilar systems in sharing information is important, but other aspects are also required in the sharing of enterprise systems knowledge. First, this process is based on the need for collaboration; sharing and mutual understanding of the needs of each stakeholder, i.e. each person involved or affected by the future information system, at each stage of its development. Second, this process follows principles, which highlight the need for formal semantic definition of these models, at various abstraction levels ranging from specification to implementation on site. There is a need to also couple new theoretical results with applied methods and tools supporting existing business reconfiguration and transformation both locally and globally.

In this editorial, we reflect on the current and future theory and applications that would further empower Knowledge engineering in networked enterprises by means of collaborative information systems. We do this inspired by the articles in this special issue, which are 8 revised extended versions (from 21 submissions) of the best papers of the $9^{\text {th }}$ International workshop on Enterprise Integration, Interoperability and Networking (EI2N'2014), and the $20^{\text {th }}$ Cooperative Information Systems Conference (CoopIS'2014), parts of the OTM Federated Conferences, held on October 27-31, 2014 in Amantea, Italy. In addition, we discuss new paradigms that may have considerable impact on Knowledge Engineering in the context of next generation enterprise information systems. 


\section{Enterprise Integration and Interoperability}

Enterprise integration is a domain of research developed from the 1990's as the extension of Computer Integrated Manufacturing (CIM). Enterprise integration research is mainly carried out within two distinct research communities: Enterprise modelling and Information Technology (IT). The notion of Enterprise Integration as it is understood in the context of enterprise modelling refers to a range of concepts and approaches including the definition of a global architecture of the system, the consistency of system-wide decision making (coherences between local and global objectives), the notion of the process which models activity flow beyond the borders of functions, the dynamic allocation of resources as well as the consistency of data [1]. It is important to recognize that enterprise integration is an essential component of enterprise engineering which concerns the set of methods, models and tools that one can use to analyse design while achieving integration [4]. Enterprise integration can be viewed in different integration levels according to the interest of the study. The European standardisation committee CEN TC310/WG1 has recognised three levels of integration: (1) Physical Integration (interconnection of devices, NC machines, PLCs, via computer networks), (2) Application Integration (dealing with interoperability of software applications and database systems in heterogeneous computing environments) and (3) Business Integration (co-ordination of functions that manage, control and monitor business processes). Integration can be obtained in terms of: (1) data (data modelling), (2) organisation (modelling of systems and processes) and (3) communication (modelling of computer networks, for example the 7-layer OSI model). Integration can be total, i.e. the standard is the software or system itself. Integration can be achieved by unification (the possible standards are methods, architectures, constructs and reusable partial models) or by federation (the possible standards are interfaces, reference models or ontologies).

Since the end of 1990's, enterprise integration approaches have to address the emerging emphasis on 'Enterprise interoperability'. Enterprise interoperability is believed to be more adaptable (less cost and quicker implementation) in decentralised, flexible and networked system environments for product and process design environments including manufacturing. Generally, interoperability refers to coexistence, autonomy and federated environments, whereas integration refers to the concepts of coordination and coherency. From the point of view of degree of coupling, the 'tightly coupled system' indicates that the components are interdependent and cannot be separated. Therefore it is the case of an integrated system. The 'loosely coupled system' refers to the components that are connected by a communication network; they can exchange services while continuing their own logic of operation. Integration is generally considered to go beyond mere interoperability to involve some degree of functional dependence [2]. While interoperable systems can function independently, an integrated system loses significant functionality if the flow of services is interrupted. An integrated family of systems must, of necessity, be interoperable, but interoperable systems do not mean they are completely integrated. Integration also deals with organisational issues, in possibly a less formalised manner due to dealing with people, but integration is much more difficult to solve. In contrast, interoperability is more of a technical issue. Compatibility is something less than interoperability. This all means that systems/units do not interfere with each other's functioning. Interoperable systems are by necessity compatible, but the converse is not necessarily true. 
Application integration concerns interoperability of applications on heterogeneous platforms. This type of integration allows access to shared data by the various remote applications. Distributed processing environments, common services for the execution environment, application program interfaces (API's), and standard data exchange formats are necessary at this level to build cooperative systems. Application integration started in the mid 1980's and is still on-going with very active work concerning STEP, EDI, HTML, XML, or eb-XML for the exchange of common shared data, development of common services for open systems around the web (web-services), integration platforms for interoperable applications in distributed environments (e.g. OSF/DCE, OMG/CORBA, WSDL, and more recently J2EE or Java to Enterprise Edition environments and .NET). Other tools used at this level are workflow management systems (WfMS) and computer support to collaborative work - CSCW [3].

\section{Knowledge Engineering for Enterprise Interoperability and networking}

Change is the modus operandi of today. Change is prevalent both in society and in technology. As the enterprise changes, so must the enterprise information systems, which operate the intra and inter communications. This change results in evolving requirements for these enterprise information systems. Only a knowledge-based engineering can facilitate context-aware systems, semantic interoperability, cyber-physical systems, cloud-based systems and interoperability assessment. A federated, omnipresent, model-driven, open, reconfigurable and aware Next Generation EIS (NG EIS) is described in [4]. The integration of the Internet of People (IoP), the Internet of Processes (IoPs), the Internet of Data (IoD), the Internet of Things (IOT) and the Internet of Services (IOS) is only possible through a NG EIS, which is enabled by knowledge engineering. Only a context aware enterprise information system can enable seamless information exchange across systems and platforms; as well as enable models that are concurrent and compatible with multiple dissimilar systems. Knowledge engineering is vital for enterprise interoperability and networking.

Knowledge engineering in production and logistics is also enabled by enterprise interoperability. Traditional information sharing is frequently executed in a logical and hierarchical manner. As enterprises adapt at a rapid pace, these inflexible approaches do not work with the agile manufacturing environment of today. Distributed approaches and technologies of control engineering and information and communication technology (ICT) to enable operational structures at the individual resource level to cooperate even at the inter- and intra-enterprises are presented in [5]. As advances in industrial control continue, the networking of the enterprise must include the production and logistics aspects and facilitate the interoperability of the enterprise. There are many challenges to making decisions from a systems perspective so as sub-optimal, locally optimized decisions are not made due to unavailable or inaccurate enterprise wide information. More widely available information enables global decisions, but raises privacy concerns. Knowledge engineering can provide a connected production and logistics system that interoperates while maintaining system security.

As previously mentioned, a top down approach is infeasible in the current enterprise. The enterprise must sense and respond to its environment, becoming a smart enterprise. The goal is to have a seamless interoperable digital enterprise model giving rise to the concept of a Sensing, Smart and Sustainable $\left(\mathrm{S}^{\wedge} 3\right)$ Enterprise System [6]. The ODP-RM (Open Distributed Processing-Reference Model presents various 
points of view, namely: Enterprise, Information, Computational, Engineering and Technological points of view. Autonomous agents are useful from multiple points of view in creating and maintain an agile enterprise model. These agents require the integration of management principles and technical features using a collaboration platform. The enterprise and its representation and use (and re-use) cannot be hierarchical to thrive as previously mentioned. However, the interoperability and the execution of the enterprise information system is only possible through a knowledge based engineering approach. All of which leads to a need for knowledge engineering for enterprise integration, interoperability and networking. This special issue contains nine articles on its theory and applications.

The first paper "Inter-enterprise Architecture as a Tool to Empower Decision Making in Hierarchical Collaborative Production Planning [7]" proposes a novel idea of inter-enterprise architecture from the enterprise engineering perspective allows collaborative networks to integrate and coordinate different organizations. Therefore, inter-enterprise architecture offers multiple benefits, including: joint process harmonization, business strategy and information technology alignment, technological cost reduction, risk and redundancies reduction, customer services improvement and enhanced responsiveness. Interenterprise architecture can be used to solve the different issues that collaborative networks face on a daily basis. A conceptual model that addresses the problem of unexpected events management in the context of hierarchical production planning to improve decision-making in collaborative environments is proposed using of inter-enterprise architectures.

In order to integrate knowledge engineering into an enterprise, and more particularly an electric power network, the paper "Enterprise Integration solution for Power Supply Company based on GeoNis Interoperability Framework [8]" introduces Smart Grid concepts for better collaboration and information sharing among different systems within such companies. The enterprise integration relies on the GeoNis integration platform which uses translators/wrappers in order to map each existing data model into the common model partially based on the CIM defined in IEC 61968 series of standards.

Organisations use Enterprise Architecture (EA) to reduce organisational complexity, improve communication, align business and information technology (IT), and drive organisational change. The paper [9] uses Archer's morphogenetic theory as a foundation to conceptualise three analytical phases of EA evolution in organisations, namely conditioning, interaction and elaboration. It proposes a model that can be used to guide professionals to manage EA and continually evolve it.

Data interoperability represents a great challenge for today's enterprises. Indeed, they use various information systems, each relying on several different models for data representation. Knowledge engineering relies on ontologies and notably ontology matching have been recognized as interesting approaches for solving the data interoperability problem. In their paper "SWRL Rule-selection Methodology for Ontology Interoperability [10]", the authors focus on improving the performance of queries addressed over ontology alignments expressed through SWRL rules. Indeed, when considering the context of executing queries over complex and numerous alignments, the number of SWRL rules highly impacts the query execution time. Moreover, when hybrid or backward-chaining reasoning is applied, the query execution time may grow exponentially. They describe a novel approach that allows, 
for a given query, to ignore unnecessary rules. The proposed Rule Selector (RS) is a middleware between the considered systems and the reasoner present on the triple store side.

To be competitive and flexible, companies involved in a collaboration have to develop and share their competences and knowledge to cope with the dynamic environment. The paper "Performance assessment architecture for collaborative business processes in BPM-SOA based environments [11]" presents an analysis and an assessment approach for collaborative business processes in the service oriented architecture in order to maintain their performance in competitive markets. The authors propose an evaluation method using execution traces of business process combined with a high level assessment method using key performance indicators.

The paper "Supporting Interoperability in Complex Adaptive Enterprise Systems: A Domain Specific Language Approach [12]" proposes an approach for supporting Enterprise Interoperability (EI) from a Complex Adaptive Systems (CAS) theory perspective. The authors are defining a theory and an infrastructure aiming at serving as a tool for solving problems in the El domain, and including a Domain Specific Language (DSL) supporting engineering interoperability solutions.

The paper "Towards a methodology for analysing the impact of business interoperability on the performance of cooperative industrial networks [13]" presents a methodology for analysing the impact of business interoperability on the performance of cooperative industrial networks. The analysis of the impact is grounded on an agent-based simulation method. A theoretical agent-based model is proposed to simulate the manner in which companies interoperate in cooperative industrial networks and how the distance between the actual and the required level of business interoperability in different dyad relationships can affect the performance of these companies.

The paper "Factory System for Dynamic Manufacturing Network supporting Networked Collaborative Product Development [14]" demonstrates, through the use of open standards that knowledge capitalization in industry aims at providing an agile infrastructure for networked collaborative product development. This paper presents a new way of combining model based enterprise platform engineering, model driven architecture, and systems engineering techniques in order to address the establishment of a sustainable interoperability.

Finally, when designing highly interactive distributed systems such as e-learning environments, a systemof-systems (SoS) perspective enables dynamic adaptation to situations of use and thus user-centeredness during operation. The paper "System-of-Systems Support - A Bigraph Approach to Interoperability and Emergent Behaviour

[15]" proposes an approach based on the interoperability assurance of systems, in particular federating various devices and cross-over in dynamically evolving environments. The authors demonstrate the utility of biograph-based handling of SoS with abstract relationships allowing not only the representation of dynamic interaction but also the re-specification of these systems through behaviour adaptations, but also the support of cross-systems decomposition as well as composition of interaction patterns for the purpose of emergent behaviour and knowledge discovery. 
The guest editors would like to thank all the authors and the reviewers who have made significant contributions and efforts to the preparation and edition of this special issue.

\section{References}

[1] Vernadat, F.B. (2002). Enterprise Modeling and Integration (EMI): Current Status and Research Perspectives. Annual Reviews in Control. 26, 15-25.

[2] Panetto H. (2007). Towards a Classification Framework for Interoperability of Enterprise Applications. International Journal of CIM, Taylor \& Francis, 20 (8), 727-740. ISSN: 0951-192X

[3] Goranson, T., Jochem, R., Nell, J., Panetto, H., Partridge, C., Sempere Ripoll, F., Shorter, D., Webb, P., Zelm, M. (2002). New Support Technologies for Enterprise Integration. IFIP International Conference on Enterprise Integration and Modelling Technology (ICEIMT'02), Kluwer Academics Publisher, Valencia, Spain, 24-26 April 2002, 347-358.

[4] Hervé Panetto, Milan Zdravković, Ricardo Jardim-Goncalves, David Romero, J. Cecil, István Mezgár. (2016). New Perspectives for the Future Interoperable Enterprise Systems. Computers in Industry, Elsevier, 2016, Special Issue: "Future Perspectives on Next Generation Enterprise Information Systems: Emerging Domains and Application Environments", 79, 47-63. <10.1016/j.compind.2015.08.001>

[5] László Monostori, Paul Valckenaers, Alexandre Dolgui, Hervé Panetto, Mietek Brdys, Balázs Csanád Csáji. Cooperative Control in Production and Logistics. Annual Reviews in Control, Elsevier, 2015, 39 (1), pp.12-29. <10.1016/j.arcontrol.2015.03.001>

[6] Georg Weichhart, Arturo Molina, David Chen, Lawrence E. Whitman, François Vernadat. Challenges and current developments for Sensing, Smart and Sustainable Enterprise Systems Computers in Industry, Elsevier, 2016, Special Issue: "Future Perspectives on Next Generation Enterprise Information Systems: Emerging Domains and Application Environments", Vol. 80. <10.1016/j.compind.2015.07.002>

[7] Alix Vargas, Andres Boza, Shushma Patel, Dilip Patel, Llanos Cuenca, Angel Ortiz, Inter-enterprise Architecture as a Tool to Empower Decision Making in Hierarchical Collaborative Production Planning. Data \& Knowledge Engineering, Elsevier, 2016, Special issue on Knowledge Engineering for Enterprise Integration, Interoperability and Networking: Theory and Applications, Guest Editors: H. Panetto and L. Whitman

[8] Leonid Stoimenov, Nikola Davidovic, Aleksandar Stanimirovic, Milos Bogdanovic, Dalibor Nikolic. Enterprise Integration solution for Power Supply Company based on GeoNis Interoperability Framework. Data \& Knowledge Engineering, Elsevier, 2016, Special issue on Knowledge Engineering for Enterprise Integration, Interoperability and Networking: Theory and Applications, Guest Editors: H. Panetto and L. Whitman

[9] Ayed Alwadain, Erwin Fielt, Axel Korthaus, Michael Rosemann. Empirical Insights into the development of a Service-oriented Enterprise Architecture. Data \& Knowledge Engineering, Elsevier, 2016, Special issue 
on Knowledge Engineering for Enterprise Integration, Interoperability and Networking: Theory and Applications, Guest Editors: H. Panetto and L. Whitman

[10] Tarcisio M Farias, Ana Roxin, Christophe Nicolle. SWRL Rule-selection Methodology for Ontology Interoperability. Data \& Knowledge Engineering, Elsevier, 2016, Special issue on Knowledge Engineering for Enterprise Integration, Interoperability and Networking: Theory and Applications, Guest Editors: $\mathrm{H}$. Panetto and L. Whitman

[11] Maroua Hachicha, Muhammad Fahad, Néjib Moalla, Yacine Ouzrout. Performance assessment architecture for collaborative business processes in BPM-SOA based environments. Data \& Knowledge Engineering, Elsevier, 2016, Special issue on Knowledge Engineering for Enterprise Integration, Interoperability and Networking: Theory and Applications, Guest Editors: H. Panetto and L. Whitman

[12] Georg Weichhart, Wided Guédria, Yannick Naudet. Supporting Interoperability in Complex Adaptive Enterprise Systems: A Domain Specific Language Approach. Data \& Knowledge Engineering, Elsevier, 2016, Special issue on Knowledge Engineering for Enterprise Integration, Interoperability and Networking: Theory and Applications, Guest Editors: H. Panetto and L. Whitman

[13] Izunildo Cabral, António Grilo, António Gonçalves-Coelho, António Mourão. Towards a methodology for analysing the impact of business interoperability on the performance of cooperative industrial networks. Data \& Knowledge Engineering, Elsevier, 2016, Special issue on Knowledge Engineering for Enterprise Integration, Interoperability and Networking: Theory and Applications, Guest Editors: H. Panetto and L. Whitman

[14] David Tchoffa, Abderrahman El Mhamedi, Nicolas Figay, Parisa Ghodous, Ersnesto Exposito, Thomas Vosgien, Lyes Kermad. Digital Factory System for Dynamic Manufacturing Network supporting Networked Collaborative Product Development. Data \& Knowledge Engineering, Elsevier, 2016, Special issue on Knowledge Engineering for Enterprise Integration, Interoperability and Networking: Theory and Applications, Guest Editors: H. Panetto and L. Whitman

[15] Chris Stary, Dominik Wachholder. System-of-Systems Support - A Bigraph Approach to Interoperability and Emergent Behaviour. Data \& Knowledge Engineering, Elsevier, 2016, Special issue on Knowledge Engineering for Enterprise Integration, Interoperability and Networking: Theory and Applications, Guest Editors: H. Panetto and L. Whitman 